\title{
Machining and surface integrity of fibre-reinforced plastic composites
}

\author{
M RAMULU \\ Department of Mechanical Engineering, University of Washington, Seattle, \\ WA 98195, USA \\ e-mail: ramulum@me.washington.edu
}

\begin{abstract}
The current focus of manufacturing research on fibre-reinforced plastics (FRP) is composed of the search for efficient processing techniques capable of providing high quality machined surfaces. Very limited work has been performed to identify the influence of manufacturing processes like edgetrimming and drilling on material performance. Recent reports suggest that process-induced damage may affect the mechanical behaviour of FRP materials. Therefore an experimental study of orthogonal cutting was conducted on the edge trimming of unidirectional and multi-directional graphite/epoxy composites with polycrystalline diamond tools. The effects of tool geometry and operating conditions were evaluated from an analysis of chip formation, cutting force, and machined surface topography. All aspects of material removal were found to be primarily dependent on fibre orientation. Discontinuous chip formation was noted throughout this study, regardless of machining parameters. Three distinct mechanisms in the edge trimming of fibre-reinforced composite material including a combination of cutting, shearing, and fracture along the fibre/matrix interface were observed. An investigation conducted on the compression, flexural and impact strength of graphite/epoxy composites machined by both traditional and non-traditional techniques, confirms that manufacturing characteristics may not only affect bulk properties but also influence the initiation and propagation of failure.
\end{abstract}

Keywords. Fibre-reinforced plastics; manufacturing processes; processinduced damage; graphite/epoxy composites.

\section{Introduction}

Fibre-reinforced plastics (FRP) are a contemporary class of multi-constituent materials which exhibit superior strength and stiffness-to-weight ratios in comparison to homogeneous counterparts. Consequently, polymeric composites are quickly gaining prominence in the aerospace, automotive, and other high technology industries, where both weight and 
performance govern design constraints. The ability to develop complicated part shapes and align fibres to accommodate for critical load orientations has facilitated the design and production of high-performance aircraft using composite materials in excess of 50 percent (Kinkaid 1988). Construction of commercial and military aircraft composed entirely of composite materials is imminent (Riggs 1984; McCarty 1993). However, specific details concerning post-mold manufacturing technology utilized for FRPs inhibit their use in new designs and in the development of new products. Contrary to net-shape manufacturing of homogeneous materials, FRPs are traditionally molded to near net shape with complicated patterns incorporating specific geometry and laminae orientation, then cured with a combination of temperature and pressure. Secondary processing such as trimming to final shape and drilling for fasteners is typically required to facilitate component assembly.

Surface roughness and tolerance are closely related, and it is generally necessary to specify a smooth finish to maintain a fine tolerance in the finishing process. For many practical design applications, tolerance and strength requirements impose a limit on the maximum allowable roughness. The reliability of machined components, especially for fibre-reinforced plastics (FRP) in high strength applications, is often critically dependent upon the quality of surface produced by machining, and the surface layer may drastically affect the strength and chemical resistance of the material. However, inhomogeneity of FRPs, caused by the difference in the properties of the fibre and the matrix materials, will have a machined surface that is less regular and is usually rougher in comparison with machined metal surfaces (Koplev et al 1983; König et al 1985; Abrate \& Walton 1992a).

Traditional methods of machining often induce critical flaws in the component parts during net trimming, and various degrees of delamination, splintering, fibre pullout, and cracking have been reported (Koplev et al 1983; König et al 1985; Ho-Cheng \& Dharan 1990; Abrate \& Walton 1992a; Colligan \& Ramulu 1992; Wang et al 1992). Due to the limitations of traditional processes, many non-traditional manufacturing methods have been examined for net shape machining of composites (Koplev et al 1983; König et al 1985; Ho-Cheng \& Dharan 1990; Abrate \& Walton 1992a; Colligan \& Ramulu 1992; Wang et al 1992). The abrasive waterjet (AWJ) is one such method which appears to be highly suited for production trimming of FRP materials (Ramulu \& Arola 1993, 1994). Owing to its ability to achieve a quality surface at rapid production rates, AWJ is currently being sought for production applications (Mortimer 1987; Miller 1991). However, very little is known regarding the effects of AWJ machining on the surface integrity of FRPs, or the influence of post-mold manufacturing defects on mechanical performance in general. Considering the present and future applications of FRP materials to commercial aerostructures and other related industries, it is necessary to obtain a fundamental understanding of postmold manufacturing process effects on the structural integrity of fibre-reinforced materials. Investigating by machining-incurred damage to mechanical performance and service life is imperative to the reliability of composite structures.

The choice of net trimming or drilling technique is often based on a combination of process economics and visual aesthetics of the machined surface. Although important, these factors are not appropriate for the choice of a manufacturing method considering the probable influence of secondary operations on the performance of composite materials. Surface roughness characteristics and surface integrity of machined FRP composites in general, and graphite/epoxy in particular, have not been studied in detail. Therefore, recent 
reports concerning machining-induced edge effects on the structural performance of FRPs are reviewed and results from an investigation on machining mechanisms and machining induced surface integrity of graphite/epoxy will be presented.

\section{Background}

\subsection{Machined quality of fibre-reinforced plastics}

Manufactured surfaces are evaluated using a number of different methods, each of which has unique quantitative features corresponding to the machined quality. The choice of inspection technique may depend on a variety of criteria including available equipment, the investigator, and other terms in which quality control guidelines are established. Mechanical performance of homogeneous material component parts has been shown to be a function of the residual stress induced in the material and the surface topography. Fibre-reinforced plastics do not develop residual stress by applied forces. Therefore, the quality of machined FRP parts is often interpreted by surface profilometry and visual techniques.

2.1a Surface morphology: Many methods have been used in evaluating the quality of FRP trimmed surfaces such as the use of average roughness parameters, c-scans, and other visual techniques. Some of these methods and associated quality criteria may be insufficient for distinguishing features that influence part performance (Philips \& Parker 1987; Griswold et al 1989; Jamil \& Chambers 1991; Wern 1991; Ramulu et al 1993). For instance, visual inspections are often used to identify the degree of damage to a component part and also to discuss prevalent topographical features. However, visual documentation provides little information that can be used in a quantitative analysis or non-subjective comparison. Ramulu and Wern (Wern 1991; Ramulu et al 1993) studied the suitability of standard roughness parameters in describing the topography of unidirectional and multidirectional graphite/epoxy $(\mathrm{Gr} / \mathrm{Ep})$ trimmed with polycrystalline diamond (PCD) tools. Various statistical and random process methods were used in addition to standard roughness parameters to analyse the trimmed surface characteristics. In this study it was found that arithmetic average surface roughness $\left(R_{a}\right)$, which is often used as a parameter for quality control, failed to describe the relative extent of surface variation observed from visual analysis. More appropriate parameters for describing topographical features of the inhomogeneous material surface include the peak-to-valley height $\left(R_{y}\right)$ and ten-point height $\left(R_{z}\right)$. Cumulative height distribution (CHD) on a probit scale and power spectrum density (PSD) function were also found very useful in characterizing the spatial distribution of the PCD trimmed graphite/epoxy material. However, one drawback of a profile based description is that matrix smearing resulting from traditional edge trimming obliterates details of the trimmed surface (Wang 1993). This implies that even in rigorous quality inspection of topography, some features remain unnoticed that may influence the structural integrity of a component part. Therefore, it is often desirable to supplement quantitative descriptions provided by profilometry with a visual analysis of the surface morphology. 
2.1b Microstructural integrity: Post-processing microstructural integrity refers to the relationship between fibre and matrix after machining. Research addressing microstructural integrity resulting from post-mold processing of FRP's is limited. Preliminary work has shown that AWJ machining of Gr/Ep does not affect the interfacial relationship between constituents whereas studies on traditional trimming and laser cutting of FRP's suggests that the fibre/matrix interface may be altered (Tagliaferri et al 1985; Wern 1991; Ramulu \& Arola 1993). Microstructure of the machined surface and accumulation of process-induced damage could prove crucial to the structural integrity of FRP's, especially when subjected to cyclic loading. In an assessment of post-mold processing influence of composite materials, microstructure should be examined and correlated with mechanical strength.

\subsection{Machining-induced edge effects on structural integrity}

The design of a FRP component is typically based on choice of constituents, distribution and orientation of the laminae, and the geometry chosen to accommodate for service loads. In addition to these parameters, the effects of manufacturing and associated defects must be considered.

2.2a Drilling effects: A handful of studies have been reported on the influence of drilled hole quality to the structural integrity of FRP materials (Wood 1978; Pengra \& Wood 1980; You \& Chou 1988; Ghasemi Nejjad \& Chou 1990; Tagliaferri et al 1990; Lin \& Lee 1992; Mehta et al 1992). Some alternatives to conventional drilling like molding holes prior to the curing process have been suggested to improve part strength of components requiring fastener holes. For instance, in a comparison with molded holes, it was recently shown that laminates with drilled holes exhibit lower tensile, compressive, and bearing strengths (You \& Chou 1988; Ghasemi Nejjad \& Chou 1990; Lin \& Lee 1992), with a reduction ranging between 20 and $70 \%$. The superior strength of panels with molded holes has been attributed to fibre continuity, an increase in fibre volume fraction near the hole vicinity, and the absence of matrix microcracks induced during drilling (Ghasemi Nejjad \& Chou 1990).

There are remarkable discrepancies between results from different investigations reported on the influence of drilling-induced hole quality to static and fatigue strength of FRP panels (Wood 1978; Pengra \& Wood 1980; Tagliaferri et al 1990; Mehta et al 1992). Wood (1978) concluded that hole quality does in fact influence the fatigue strength of composite panels but does not noticeably influence the tensile strength. Pengra \& Wood (1980) similarly concluded from experimental work that restrictions on chipout defects (pitting) and oversize holes could not be relaxed (from definitions in 1980) but suggested that quality control requirements for exit delamination in graphite/epoxy may be too stringent. On the other hand, Mehta et al (1992) found that hole quality in PMR-15/Gr laminate, particularly including exit ply delamination, may influence both tensile and compressive properties of panels with drilled holes. Tagliaferri et al (1990) concluded that although hole quality does not influence the tensile properties of composites, it has significant influence on bearing strength. Although results from these studies are inconclusive, they unquestionably suggest that drilling-induced fastener hole quality influences the mechanical behaviour of FRP materials. Since drilled-hole anomalies are consistent with those generated during traditional 
edge-trimming of FRP's, it should be rationalized that net-trimming operations and manufacturing induced defects may influence the structural integrity of FRP component parts.

2.2b Edge finishing effects: In addition to the choice of constituents, one of most important parameters affecting the mechanical properties of a FRP laminate material is component lay-up. Pipes and Pagano (1970) studied the influence of stacking sequence on the development of interlaminar shear and interlaminar normal stresses in FRP laminates subjected to external loading. These phenomena are commonly referred to as "free edge effects". Edge effects coupled with the presence of manufacturing defects on the trimmed edge may prove critical to component performance. Large magnitude interlaminar stresses at the free edge necessary to compensate for force and moment equilibrium between plies increases the need for maintaining high edge quality during net-shape trimming. Edge trimming damage of FRP component panels could be critical to the stress transfer mechanisms at the free edge.

Howarth and Strong (1990) investigated the influence of machining induced edge effects by abrasive waterjet (AWJ) and laser cutting on the strength of FRP materials. Tensile specimens of various widths were machined with both laser and AWJ methods from fiberglass, Kevlar, and graphite fibre epoxy matrix composites. In tests conducted with Kevlar fibre composites, tensile strength and modulus decreased with decreasing specimen width associated with the influence of manufacturing induced edge effects. However, from testing of fiberglass composites, specimens machined with the laser decreased with decreasing specimen width but abrasive water jets specimen tensile strength increased with decreasing specimen width. Graphite fibre composites machined with the AWJ showed the same trend, increasing tensile strength with decreasing specimen width. Laser machined Gr/Ep specimens were not tested due the poor cut quality resulting from thermal properties of the graphite fibres. No explanation was provided to support the unusual experimental results and no subsequent studies have been reported. Sadat (1988), on the other hand, examined the influence of cutting parameters on process damage and resulting interlaminar tensile strength of unidirectional Gr/Ep composites machined with a 60 tooth high speed steel (HSS) slot saw. From an optical study of the machined surface, damage features in the form of cracks, delamination, and fibre rotation were noted within the machined region. The extent of machining damage decreased with increasing cutting speed corresponding to the decrease in cutting forces monitored in both the feed and normal directions. Furthermore, minimizing machining damage with high cutting speeds resulted in an increase in the interlaminar tensile strength.

Based on this brief review of machining effects on the surface integrity of FRP materials, it appears that the choice of processing techniques as well as the process conditions used in machining may be significant. However, only a limited degree of work has been done in this area, and current knowledge of machining influence on surface integrity is insufficient. Additional investigations are necessary to enhance the understanding of manufacturing effects on FRP material performance. Therefore, an investigation on the surface integrity of graphite/epoxy was conducted at the University of Washington was started about ten years ago to study the influence of edge-trimming with polycrystalline diamond tools, diamond abrasive cutters, and abrasive waterjets on the compression and flexural strength of graphite/epoxy composites. 


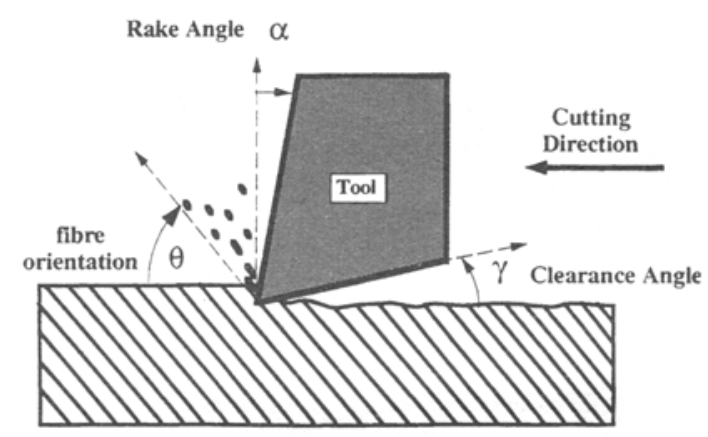

Figure 1. Fibre orientation and insert geometry.

\section{Orthogonal machining}

\subsection{Materials and procedures}

A unidirectional 4mm thick graphite/epoxy (Gr/Ep) panel with 3501-6 resin and IM-6 fibres was used in this investigation. A $1 \mathrm{~m}$ square unidirectional panel was fabricated into test specimens with the desired fibre orientations for orthogonal trimming. Fibre orientations are defined clockwise with reference to the cutting direction as shown in figure 1. Unidirectional fibre orientations greater than $90^{\circ}$ are typically regarded as negative orientations by convention. A multidirectional $\mathrm{Gr} / \mathrm{Ep}$ laminate panel with $6 \mu \mathrm{m}$ fibre diameter, 0.68 volume fraction, and $200 \mu \mathrm{m}$ ply thickness was used for the edge-trimming experiments. Panel layup of $\left[45^{\circ} /-45^{\circ} /\left(0^{\circ} / 90^{\circ} / 45^{\circ} /-45^{\circ}\right)_{2}\right]_{s}$ eliminated stretching/bending coupling and resulted in less chance of delamination and debonding. PCD tool inserts in the trimming experiments were medium grade General Electric COMPAX 1300 with $7 \mu \mathrm{m}$ grain size. Various tool insert geometries were studied including $0^{\circ}, 5^{\circ}$, and $10^{\circ}$ rake angles $(\alpha)$ with $7^{\circ}$, and $17^{\circ}$ clearance angles $(\gamma)$. Mechanical properties of the PCD material and unidirectional $\mathrm{Gr} / \mathrm{Ep}$ are listed in table 1 .

A Rockford planer-shaper equipped with a hydraulic table to provide steady cutting motion was used for the orthogonal edge-trimming experiments. On-line dynamic cutting

Table 1. Mechanical properties of PCD and Gr/Ep.

\begin{tabular}{lccc}
\hline Property & \multicolumn{3}{c}{ Material } \\
\cline { 2 - 4 } & \multicolumn{3}{c}{ Graphite/Epoxy } \\
\cline { 2 - 4 } Tensile strength (MPa) & 1378 & $90^{\circ}$ \\
Tensile modulus (GPa) & $117.0-138.0$ & 41 \\
Compressive strength (MPa) & 1309 & $8.0-11.0$ \\
Compressive modulus (GPa) & $107.0-124.0$ & N/A \\
\hline & & PCD & \\
\hline Knoop hardness (HK) & & $3400-3700$ \\
Compressive strength (GPa) & & 700 & \\
Modulus of elasticity (GPa) & & $827-1103$ & \\
TRS (MPa) & & $482-1723$ & \\
Thermal conductivity (W/m $/ \mathrm{m}^{\circ} \mathrm{C}$ ) & & $50-92$ & \\
\hline
\end{tabular}


Table 2. Edge trimming test matrix.

\begin{tabular}{|c|c|c|c|c|c|c|c|}
\hline Graphite/epoxy fibre orientation & & & ${ }^{\circ}, 15^{\circ}$ & $45^{\circ}$ & $75^{\circ}$ & & \\
\hline PCD insert & $\alpha$ & $0^{\circ}$ & $0^{\circ}$ & $5^{\circ}$ & $5^{\circ}$ & $10^{\circ}$ & $10^{\circ}$ \\
\hline Geometry & $\gamma$ & $7^{\circ}$ & $17^{\circ}$ & $7^{\circ}$ & $17^{\circ}$ & $7^{\circ}$ & $17^{\circ}$ \\
\hline Cutting speed & \multicolumn{7}{|c|}{4,9, and $14 \mathrm{~m} / \mathrm{min}$} \\
\hline Depth of cut & \multicolumn{7}{|c|}{$0.127,0.254$, and $0.381 \mathrm{~mm}$} \\
\hline
\end{tabular}

characteristics were recorded with a CCD Hi-8 format camera. Cutting forces were measured using a 3-dimensional circular-type strain gauge dynamometer attached to the tool post.

Machining tests were conducted following a full factorial design of experiments, incorporating the conditions listed in table 2 . All machining was carried out under dry cutting conditions conforming to industrial specifications. Methods of analysis included both $i n$-situ and post-process measurements of machining characteristics. In-situ analysis techniques consisted of optical recording of chip formation and cutting force measurements along the principal and thrust directions via the 3-axis dynamometer. All aspects of chip formation from inception through chip release were recorded. Surface topography and machined-surface characteristics were examined using profilometry and SEM. Surface roughness measurements were obtained by a Federal Surfanalyzer 4000 with a $5 \mu \mathrm{m}$ diameter diamond stylus probe, $0.8 \mathrm{~mm}$ cutoff length, $1.25 \mu \mathrm{m}$ measurement interval, and a $3.5 \mathrm{~mm}$ sampling length. Microstructure of the machined surface was evaluated with a Jeol JSM-T330A scanning electron microscope to supplement surface roughness measurements and provide a qualitative view of machining process damage. Details of this part of study can be found in Wang et al (1995).

\subsection{Results and discussion}

In this study it was found that chip formation was critically dependent on the fibre orientation (Wang et al 1995). The change in chip formation with fibre orientation was clearly visible by examination of the macrochip. Discontinuous chip formation was observed both in unidirectional and multidirectional laminate machining.

3.2a Cutting mechanisms: Cutting mechanisms present in machining of FRP materials in this study are shown schematically in figure 2 . For the $0^{\circ}$ material, chip formation mechanisms were composed of mode I loading and fracture along the fibre/matrix interface, mode II loading through tool advancement, and fracture perpendicular to the fibre direction under bending loads. In positive fibre orientations between $15^{\circ}$ and $75^{\circ}$, the chip formation mechanisms included fracture from compression-induced shear across the fibre axis combined with interfacial shearing along the fibre direction during chip advancement. Chip flow in trimming all posiitiv orientations up to and including $90^{\circ}$ material occurred on a plane parallel to the fibre orientation. Material removal in nearly all positive fibre orientations, therefore, appears to be governed by the in-plane shear properties of the unidirectional material. Chip formation for fibre orientations greater than $75^{\circ}$ is primarily 


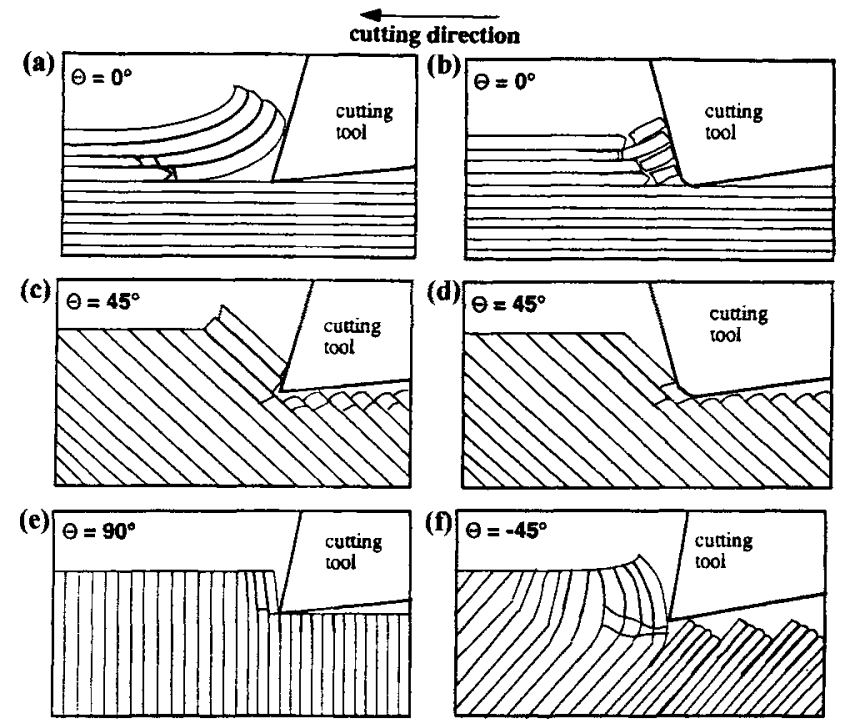

Figure 2. Cutting mechanisms in the orthogonal machining of $\mathrm{Gr} / \mathrm{Ep}$. (a) Delamination; (b) fibre buckling; (c) \& (d) fibre cutting; (e) deformation; (f) shearing.

compression-induced fracture perpendicular to the fibres and interlaminar shear fracture along the fibre/matrix interface. These mechanisms are consistent with those previously documented by others (Koplev et al 1983; Sakuma \& Seto 1983; Kaneeda 1991; Krishnamurthy et al 1992). Edge trimming of large fibre orientations is frequently accompanied by out-of-plane displacement and material fracture ahead of the cutting tool. Based on the results for multi-directional laminates, orthogonal cutting mechanisms for all fibre orientations were distinguished. The cutting mechanisms of $0^{\circ}$ and $45^{\circ}$ plies in edge trimming of multi-directional laminates were identical to those of equivalent unidirectional fibre orientations. Conventional trimming of $0^{\circ}$ plies with the PCD tools occurred by a combination of mode I and mode II loading and subsequent fracture. Mechanisms of chip formation and material removal for $45^{\circ}$ plies originate from shear loading. Fracture occurred perpendicular to the fibre axis within the compressive field of the contact zone, and fibre/matrix interface shear permitted chip flow. However, chip formation mechanisms in trimming $90^{\circ}$ and $-45^{\circ}$ unidirectional material were slightly different from that for multi-directional laminates as a result of the influence of adjacent plies. When machining unidirectional composites with fibre orientations of $90^{\circ}$ or more, extensive degrees of out-of-plane damage occurred. In contrast, support provided from adjacent plies in the multi-directional ply structure allowed for machining with relatively small degrees of structural degradation. Trimming damage associated with $90^{\circ}$ plies of the multi-directional laminate was limited to a loss of fibre/matrix cohesion evident at the trimmed surface. Damage to the $-45^{\circ}$ plies was more extensive through shear failure along the fibre/matrix interface and fracture perpendicular to the fibre direction beneath the trimming plane. Tool geometry appeared to have no discernible effect on the degree of trimming damage. In-situ chip formation analysis in edge-trimming the multi-directional $\mathrm{Gr} / \mathrm{Ep}$ laminate revealed the formation of discontinuous chips progressing along the rake face. These features were 
similar to features of chip formation evident in trimming unidirectional material with fibre orientations greater than $90^{\circ}$ (negative orientations). In general, chip lengths on trimming the laminate were larger than those obtained in trimming unidirectional material. Postprocess characteristics of chip formation observed in edge-trimming the multi-directional laminate were also quite similar to those of unidirectional $\mathrm{Gr} / \mathrm{Ep}$, particularly in the $0^{\circ}$ and $45^{\circ}$ plies. Fragmented chips attributed to split failure ahead of the cutting tool were produced in the trimming of $0^{\circ}$ plies. Very tiny chips were noted from $45^{\circ}$ plies with chip release along the fibre direction. The fracture plane for both $0^{\circ}$ and $45^{\circ}$ fibre orientations was parallel to the fibre direction as in the case of $90^{\circ}$ plies. However, contrary to trimming unidirectional $\mathrm{Gr} / \mathrm{Ep}$, tiny chips were produced in $90^{\circ}$ laminate plies without any indication of out-of-plane displacement. Material damage was essentially eliminated due to support provided by adjacent plies in the multi-directional lay-up. Similarly, chips produced from trimming $-45^{\circ}$ plies of the laminate resulted in severe damage below the trimming plane, but the extent of damage was limited due to support provided by adjacent plies.

3.2b Cutting forces: In support of chip formation dependence on fibre orientation, principal cutting and thrust forces in this study were primarily influenced by fibre orientation; operating conditions and tool geometry had very little influence. Principal cutting forces ranged from $100 \mathrm{~N}$ for $0^{\circ}$ to slightly more than $800 \mathrm{~N}$ for $90^{\circ}$ material. Specific cutting energy ranged from $1 \times 10^{8}$ to $7.8 \times 10^{8} \mathrm{~J} / \mathrm{m}^{3}$, significantly lower than that documented from orthogonal trimming of conventional homogeneous materials (Koplev et al 1983). Contrary to the mechanics of chip formation in metal cutting, the thrust force was nearly always greater than the corresponding principal force except when trimming material with fibre angles of $0^{\circ}$, and greater than or equal to $90^{\circ}$, as shown in figure 3 . In general, thrust forces commonly increased with fibre orientation up to $45^{\circ}$, and then decreased to $90^{\circ}$. High thrust forces may be attributed to the elastic recovery of the fibres within the contact zone prior to fracture. The elastic energy of the deformed fibres, released when the fibres are severed, imparts a thrust force on the tool flank and is a potent source for tool wear. This analogy is supported by the fact that the thrust force in trimming $0^{\circ}$ and $90^{\circ}$ orientations is almost the same as they undergo the least bending-induced elastic deformation. These results are consistent with results reported by Koplev (1980), Sakuma \& Seto (1983), and Inoue \& Ido (1986) but not with those of Kaneeda (1991).

Features of the cutting force profiles in trimming multi-directional laminate were nearly identical to those recorded in edge trimming $90^{\circ}$ unidirectional material. The force profiles exhibited a high frequency fluctuation in cutting force $\left(F_{c}\right)$. However, tool geometry affected the magnitude of both $F_{c}$ and its fluctuation in trimming of the multi-directional laminate. Compounded effects of tool rake and clearance angles on the principal and thrust cutting forces are shown in figures $4 \mathrm{a}, \mathrm{b}$; a depth of cut $(t)$ of $0.13 \mathrm{~mm}$ and $9 \mathrm{~m} / \mathrm{min}$ cutting speed $(V)$ were used for the simulations. Optimal rake angle $(\alpha)$ in terms of minimizing the principal cutting force was determined to be approximately $7^{\circ}$ as shown in figure 4 a. Thrust force, however, increased with increasing rake angle but decreased with increasing clearance angle. The optimal tool geometry for minimizing the resultant cutting force over the range of operating conditions in this study would consist of a tool with $6^{\circ} \sim 7^{\circ} \alpha$ and 

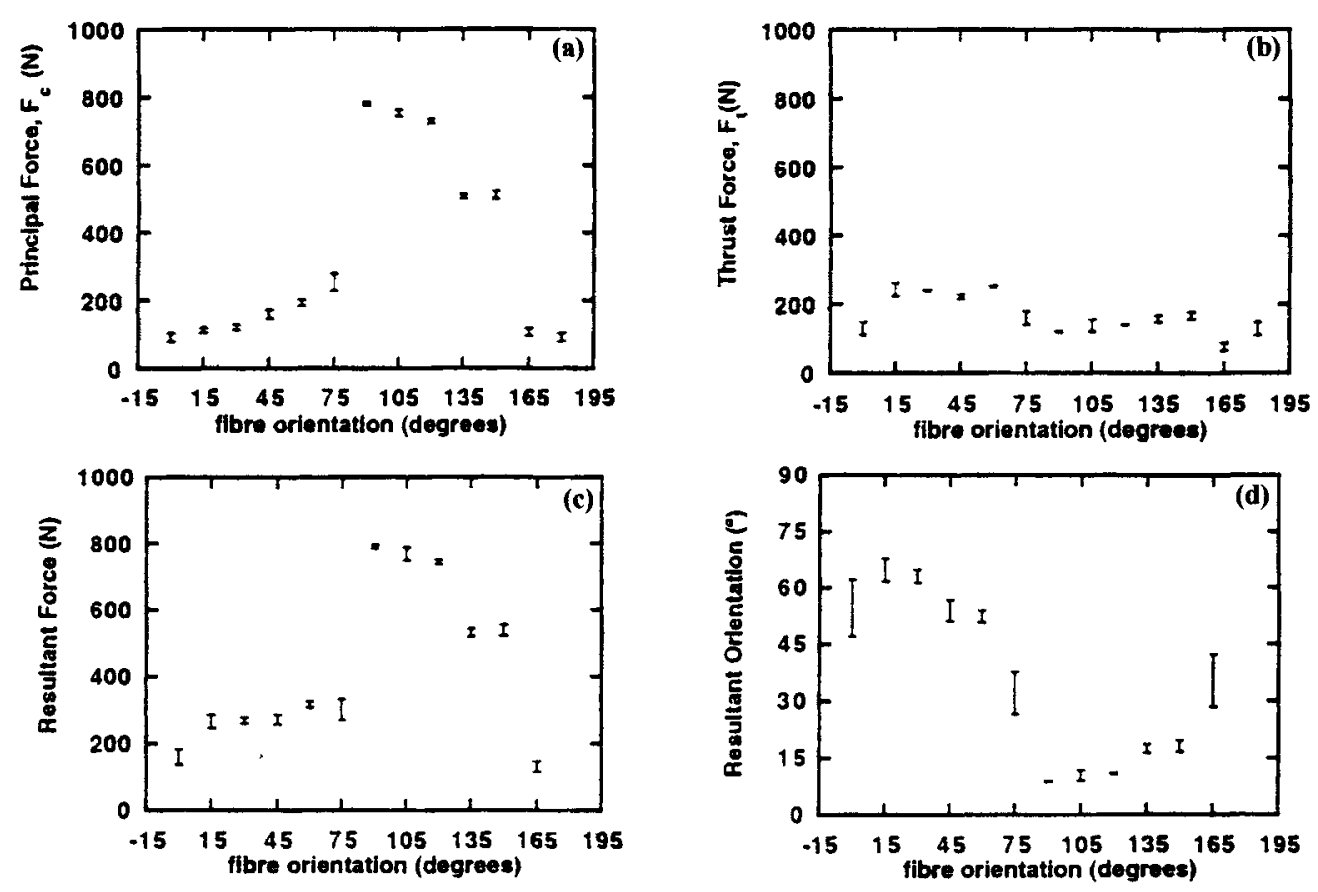

Figure 3. Cutting forces in edge-trimming with a $10^{\circ} \alpha / 17^{\circ} \gamma$ PCD tool. Cutting conditions: $4 \mathrm{~m} / \mathrm{min}$ cutting speed, $0.25 \mathrm{~mm}$ depth of cut. (a) Principal cutting force; (b) thrust force; (c) resultant cutting force; (d) resultant force orientation.

$17^{\circ} \gamma$ angles. Increasing the clearance angle beyond $17^{\circ}$ would result in lower thrust and hence resultant forces, but would ultimately result in a reduction of tool life. The optimal tool geometry to minimize cutting forces in orthogonal trimming of $\mathrm{Gr} / \mathrm{Ep}$ in this study is in excellent agreement with that reported by Park (1991), which was generated from the aspect of minimizing tool wear.

Over the range of cutting speeds available from the planer/shaper machine $(V<$ $20 \mathrm{~m} / \mathrm{min}$ ), essentially no change in cutting force was noted. However, principal cutting force increased linearly with depth of cut and in turn influenced the magnitude of the resultant cutting force and its orientation with respect to the plane of trimming. Although principal cutting force decreased with increasing rake angle, smaller resultant cutting forces were obtained with $\mathrm{a} 0^{\circ}$ rake angle tool rather than positive rake angle $\mathrm{PCD}$ inserts due to the influence of thrust forces. In addition, smaller cutting forces were obtained for a $17^{\circ}$ clearance PCD insert rather than a $7^{\circ}$ clearance angle.

3.2c Surface roughness: Surface quality in orthogonal trimming of FRP materials is closely related to chip formation and, hence, fibre orientation. Due to the unique chip formation mechanisms of the $0^{\circ}$ fibre orientation and bare fibres on the machined surface, $R_{a}$ and $R_{y}$ values in the longitudinal direction were usually higher than those in positive fibre orientations. The average surface roughness of fibre orientations from $15^{\circ}$ to $60^{\circ}$ in both longitudinal and transverse measurement directions exhibited high quality with 
(a)
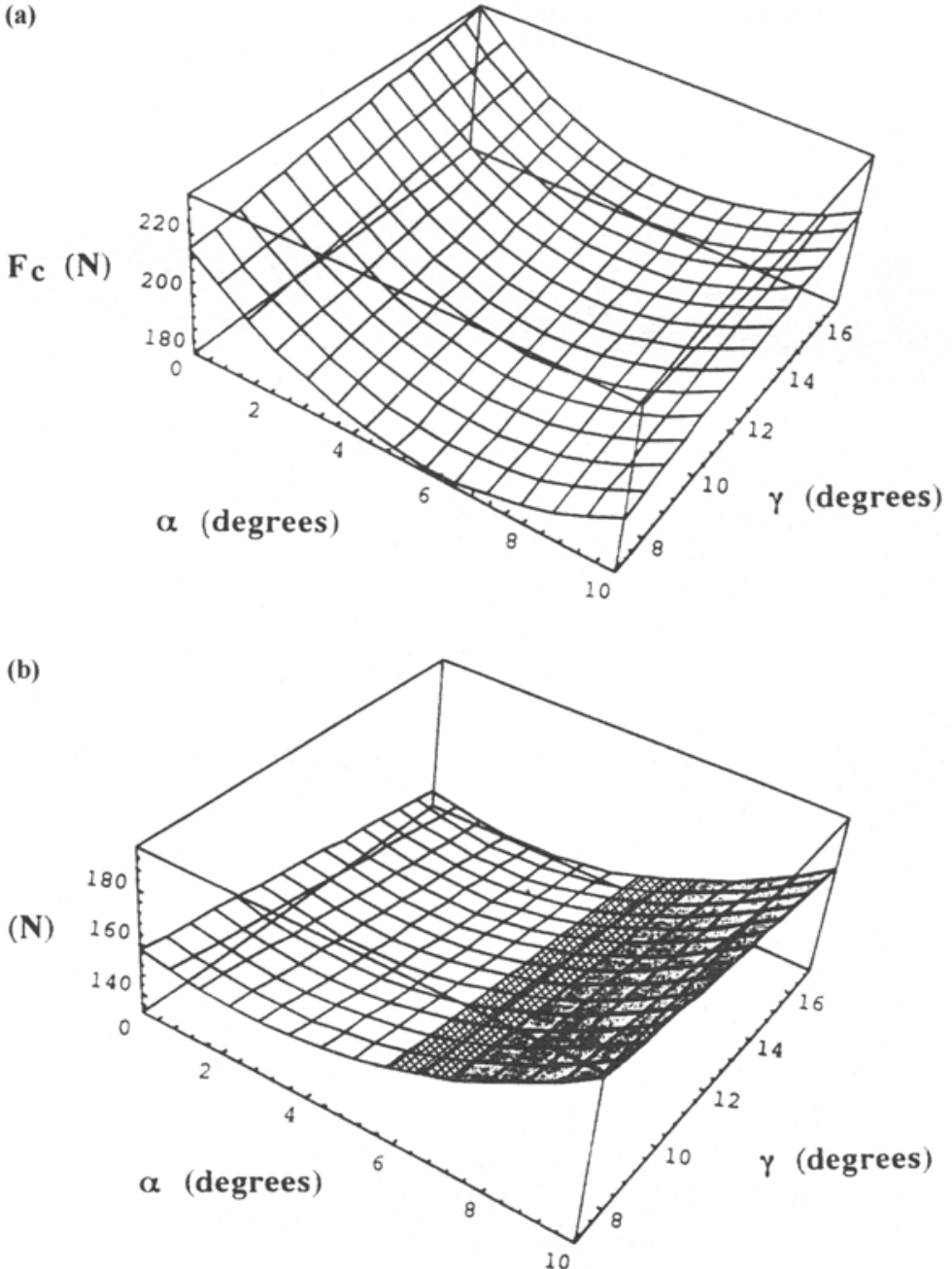

Figure 4. Effect of tool geometry on the cutting forces. Cutting conditions: $4 \mathrm{~m} / \mathrm{min}$ cutting speed, $0.13 \mathrm{~mm}$ depth of cut. (a) Principal cutting force; (b) thrust force.

roughness between 1 and $1.5 \mu \mathrm{m}$. Very few changes were noted in roughness measurements between fibre orientations of $15^{\circ}$ and $60^{\circ}$. Surface texture measurements were not obtained for positive orientations greater than $60^{\circ}$ or negative orientations due to severe cutting damage as previously discussed. Peak-to-valley height $\left(R_{y}\right)$ values in figure 5 exhibited trends similar to longitudinal and traverse direction $R_{a}$ measurements though with a more sensitive response to fibre orientation.

Surface roughness measurements for laminate composites were significantly influenced by the variation in ply angles and measurement direction. Matrix smearing was dominant on $45^{\circ}$ and $90^{\circ}$ fibre plies, and bare fibres were usually observed on the $0^{\circ}$ ply. The dominant feature of $-45^{\circ}$ plies was the "in-depth" damage due to fibre pullout and intralaminar cracking (delamination) which induced deep valleys in profile measurements taken transverse to the trimming direction. Longitudinal measurements taken parallel to the cutting 
(a)
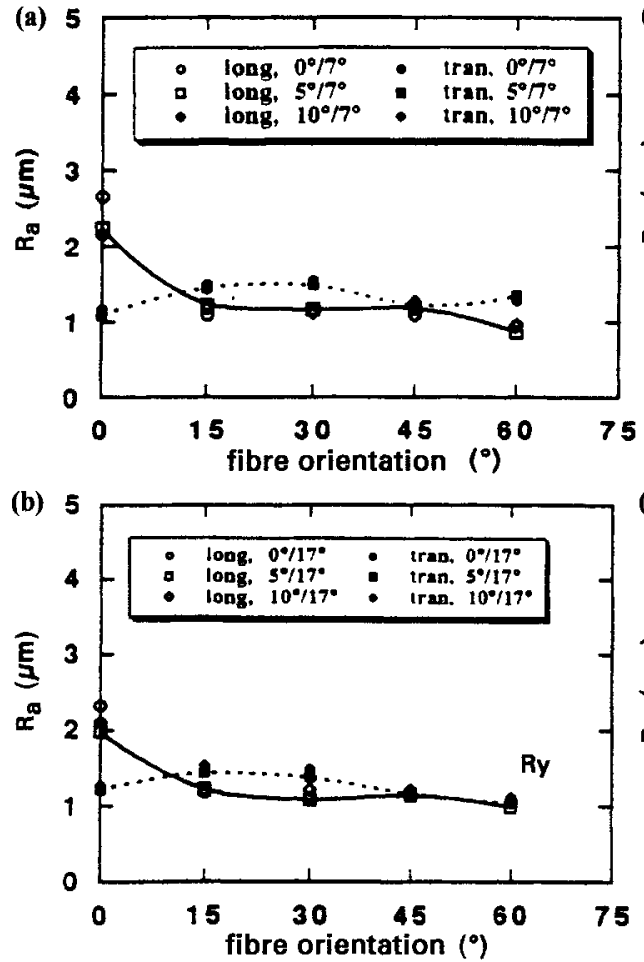

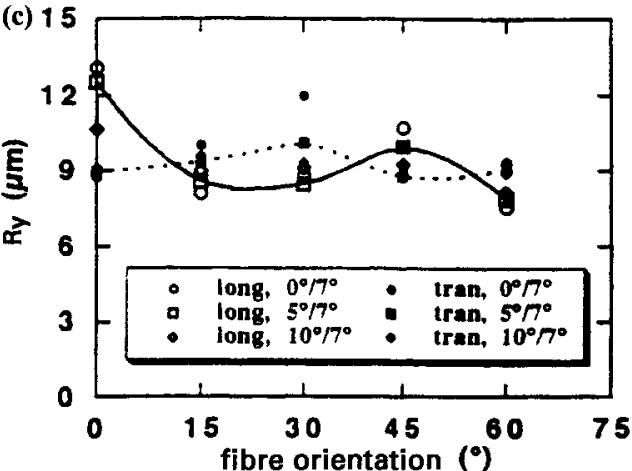

(d) 15

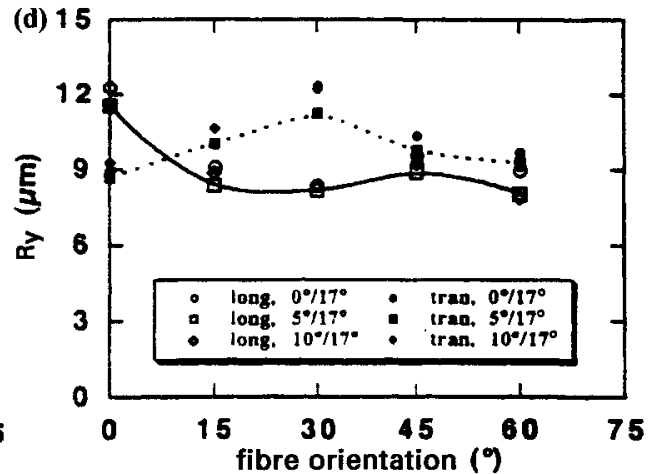

Figure 5. Tool-geometry influence on surface texture. Cutting conditions: $9 \mathrm{~m} / \mathrm{min}$ cutting speed, $0.25 \mathrm{~mm}$ depth of cut. Average roughness with $7^{\circ} \gamma(\mathbf{a})$; and $17^{\circ} \gamma$ (b) average peakto-valley height with $7^{\circ} \gamma(\mathbf{c})$ and $17^{\circ} \gamma(\mathbf{d})$.

direction did not indicate the extent of trimming damage, even when acquired on the $-45^{\circ}$ plies as shown in figure 6 . Therefore, average surface roughness $\left(R_{a}\right)$ and maximum height roughness $\left(R_{y}\right)$ alone do not appear capable of indicating the "true" surface quality of a trimmed FRP without additional methods of observation. A combination of standard roughness parameters and a statistical representation of profiles taken perpendicular to the feed direction as shown in figure 6 may be more appropriate for a qualitative inspection.

\subsection{Conclusions}

Orthogonal cutting mechanisms in the edge-trimming of graphite/epoxy laminates with polycrystalline diamond tools were studied. Chip formation, cutting force, and surface morphology were evaluated with respect to tool geometry, process conditions, and ply distribution in the laminate. As with the trimming of unidirectional panels, discontinuous chips were observed with primary dependence on fibre orientation. Cutting mechanisms for $0^{\circ}$ and $45^{\circ}$ plies were identical to those in the trimming of unidirectional material. However, chip-formation mechanisms in trimming $90^{\circ}$ and $-45^{\circ}$ plies of the multi-directional laminate changed due to the support provided by adjacent plies. 

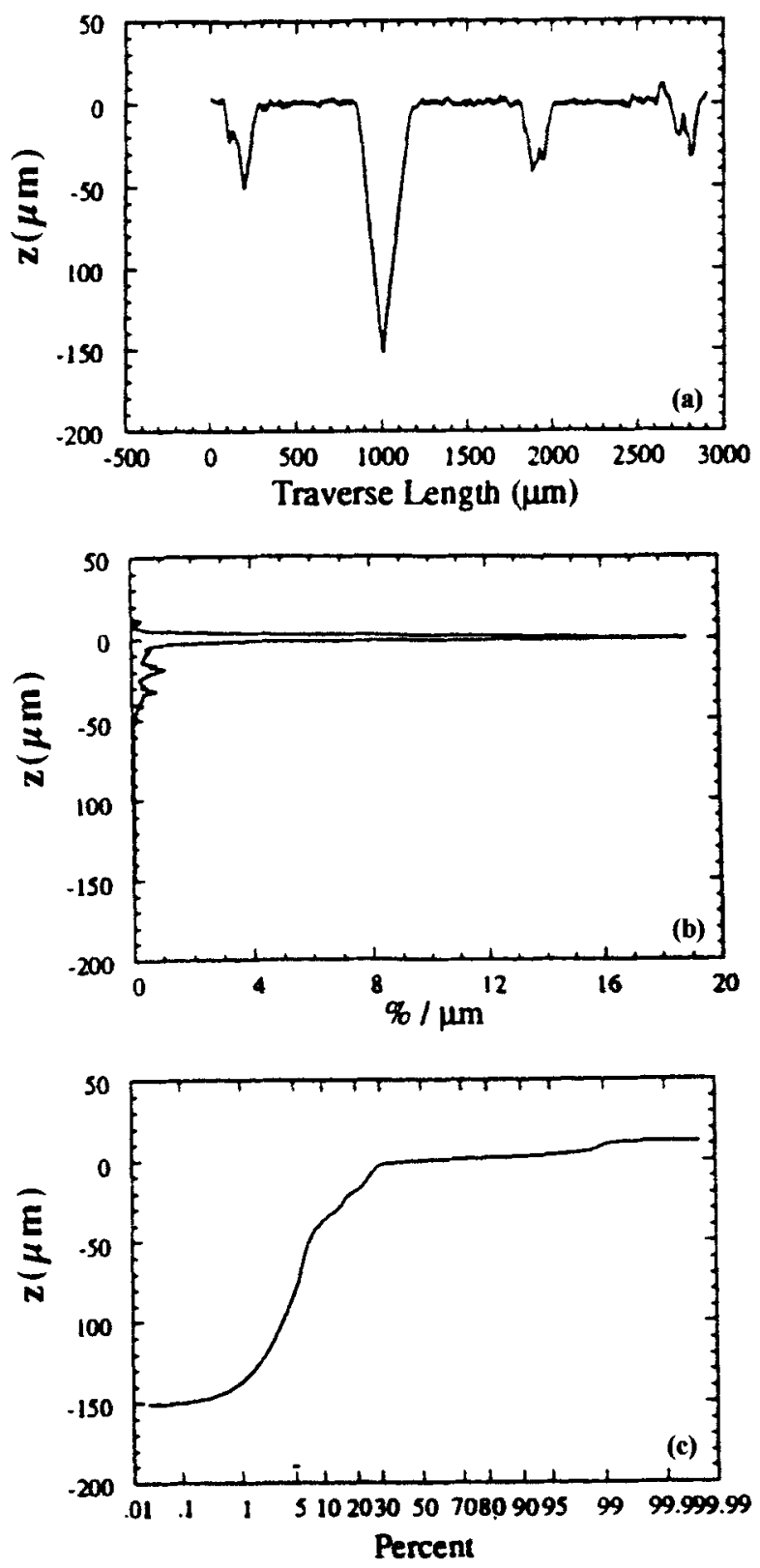

Figure 6. Transverse profile of the Gr/Ep laminate. Cutting conditions: $4 \mathrm{~m} / \mathrm{min}$ cutting speed, $0.25 \mathrm{~mm}$ depth of cut, $0^{\circ} \alpha / 17^{\circ} \gamma$ tool. (a) Profile height; (b) probability density of profile height; (c) cumulative height distribution. 


\section{Surface integrity}

\subsection{Materials and procedures}

Graphite/epoxy laminate material with 3501-6 resin and IM-6 fibres was used for all experiments in this preliminary investigation. Compression specimens were composed of plies of unidirectional tape $\left(0^{\circ}\right.$ plies), plain-weave fabric $\left(0^{\circ} / 90^{\circ}\right)$, and bias-weave fabric $\left(45^{\circ} /-45^{\circ}\right)$. Flexure specimens consisted of unidirectional tape laminated with combinations of $0^{\circ}, 90^{\circ}, 45^{\circ}$, and $-45^{\circ}$ plies. Panels used for both phases of testing were hand laminated with lay-up indicative of that used in aerospace structures.

Compression specimens were acquired from a bulk laminate panel using either diamond abrasive cutters or AWJ machining according to a standard aerospace coupon design (Colligan 1993). All specimens were first rough-machined with a \#30 grit diamond abrasive cutter. A test section of the dog-bone specimen was obtained using either diamond abrasive cutters or the abrasive waterjet incorporating various parametric conditions which provided a range in edge quality received from each machining technique. Flexure and impact specimens were obtained using three manufacturing techniques, namely traditional trimming with polycrystalline diamond (PCD) cutting tools, AWJ machining, and diamond-saw machining with a \#220 garnet diamond-impregnated slot saw. Cutting conditions used in obtaining the compression and flexure specimens are available in Colligan (1993) and Arola \& Ramulu (1994) respectively. Surface profiles of the machined specimens were obtained using a stylus profilometer according to ANSI B46.1-1985. Surface topography of the machined specimens was analysed from profile data using standard roughness parameters, statistical methods, and random process methods in addition to visual techniques. Details concerning analysis procedures are provided in the aforementioned references.

An MTS Universal Test Machine was used for compression tests with a stroke rate of $0.8 \mathrm{~mm} / \mathrm{min}$, hydraulic grips, and buckling constraint. An extensometer was used to record strain data. Flexure and impact specimens were loaded to failure according to ASTM standard D790M (ASTM 1986). Four-point and three-point flexure configurations were used with 16-to-1 span-to-depth ratio. Machined edges of the flexure and impact specimens were parallel to the plane of applied load. Testing performed in both modes of loading was performed at ambient temperature and humidity. Ultimate load and associated failure phenomena were correlated with qualitative data of the machined specimens to study the influence of manufacturing and surface quality on mechanical performance under compression and bending loads.

\subsection{Results and discussion}

Study of machining influence on the performance of Gr/Ep subjected to compression and pure bending under four-point loading was conducted (Colligan 1993; Arola \& Ramulu 1994). Prior to conducting strength analysis, topographies of the machined surfaces obtained with each method of machining were analysed using profilometry. Typical profiles obtained from the machined surface of diamond-saw, PCD-trimmed, and AWJ-machined specimens as well as the profile probability density, and cumulative height distribution are shown in figures $7 \mathrm{a}-\mathrm{c}$ respectively. Profiles in figure $7 \mathrm{a}$ were obtained perpendicular to 


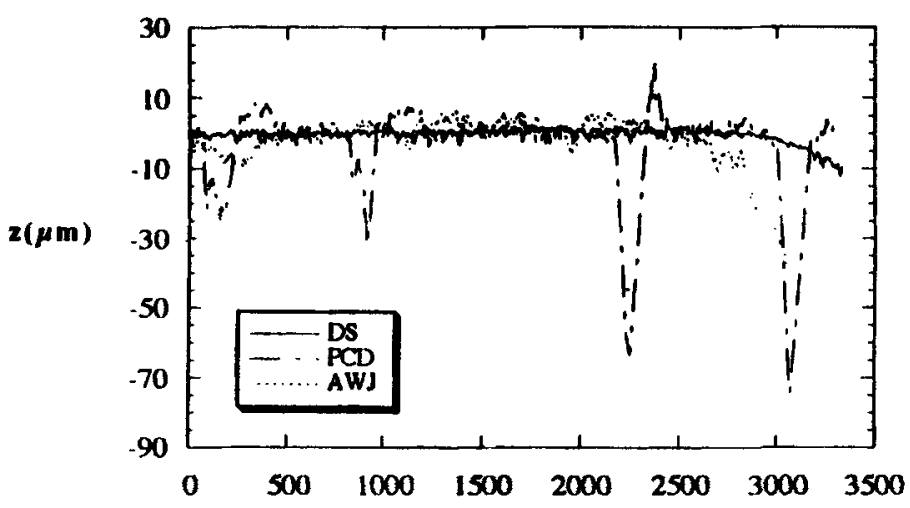

(a)

Traverse Length (um)

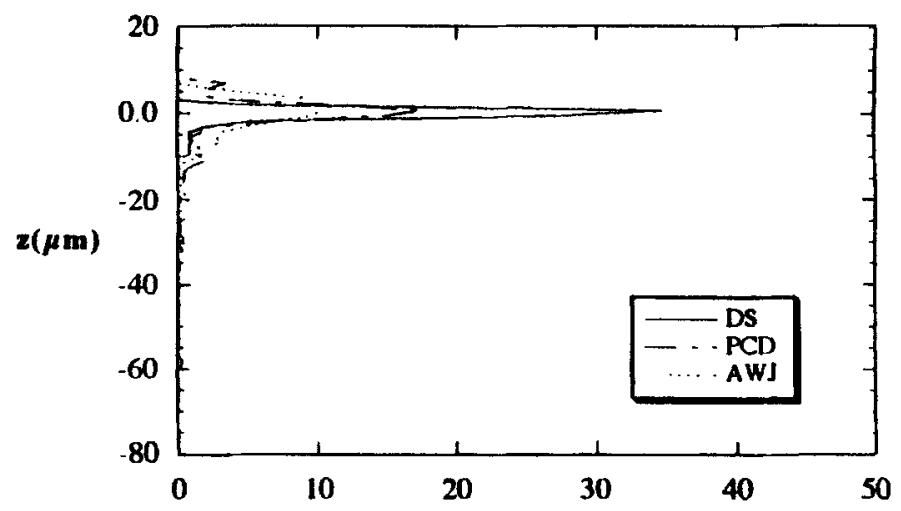

(b)
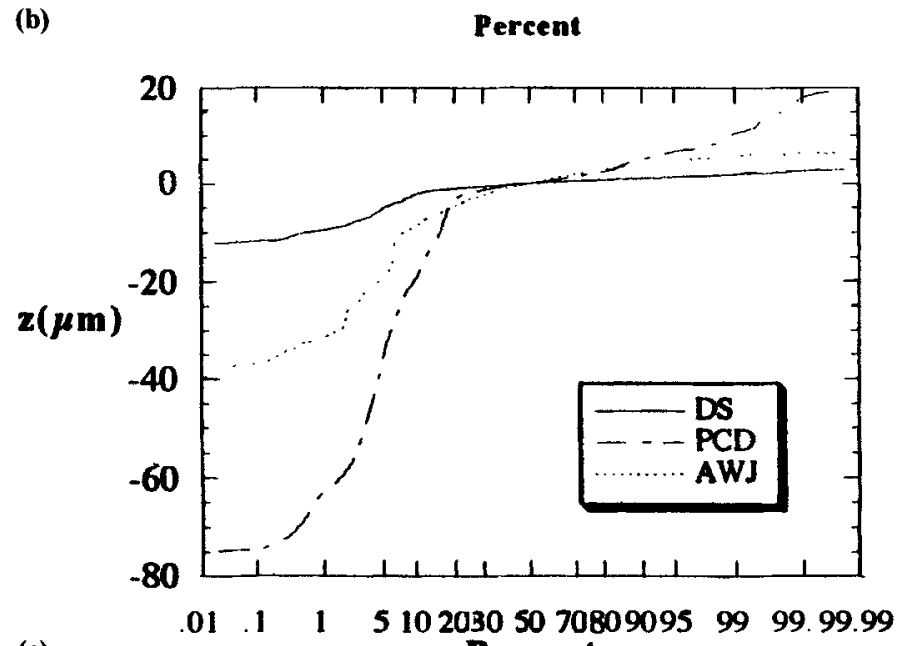

(c) Percent

Figure 7. Flexure specimen transverse profilometry. (a) Profile height; (b) profile height density; (c) cumulative height distribution. 


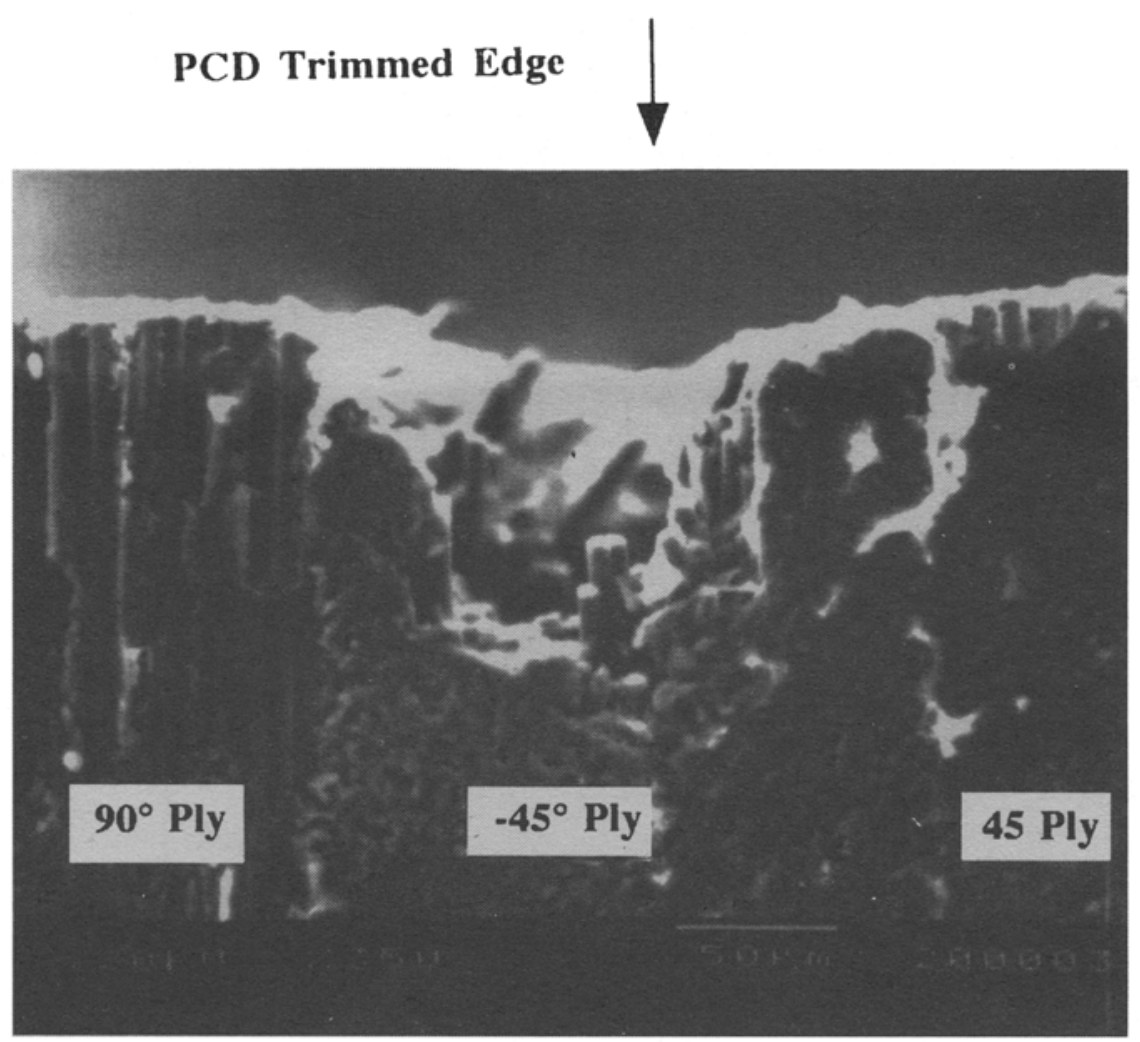

Figure 8. Damage to $45^{\circ}$ ply of PCD edge-trimmed Gr/Ep laminate.

the major axis (feed direction). In general, all three techniques produced relatively high quality machined surfaces. However, although the average surface roughness $\left(R_{a}\right)$ of the PCD specimens ranged between 1 and $2 \mu \mathrm{m}$, extensive fibre pullout occurred with the $-45^{\circ}$ plies as evident in figure 8. Plies in this orientation exhibit fibre direction with slope opposite to the cutting direction and commonly fail along the fibre/matrix interface during traditional edge-trimming. Compression specimens obtained with the AWJ and diamond abrasive cutters were machined at process conditions that provided a wide range in surface quality. Average surface roughness of specimens fabricated with each technique ranged from 5 to $25 \mu \mathrm{m} R_{a}$.

Following the qualitative inspection of the machined surfaces, compression, flexural and impact testing was conducted. While recording the stress strain response of compression specimens, it was noted that the AWJ-machined specimen loading response appeared to be a function of surface quality. Typical stress strain curves for three AWJ machined specimens of differing quality are shown in figure 9. Initiation and propagation of failure occurred first in the specimens with high surface roughness and exit ply delamination. Typical load displacement histories for PCD-trimmed, diamond-saw and AWJ-machined flexure specimens are shown in figure 10. Load deflection curves obtained during application of the bending load consistently suggested that permanent damage, i.e. failure initiation and propagation, occurred first in PCD-trimmed specimens. 


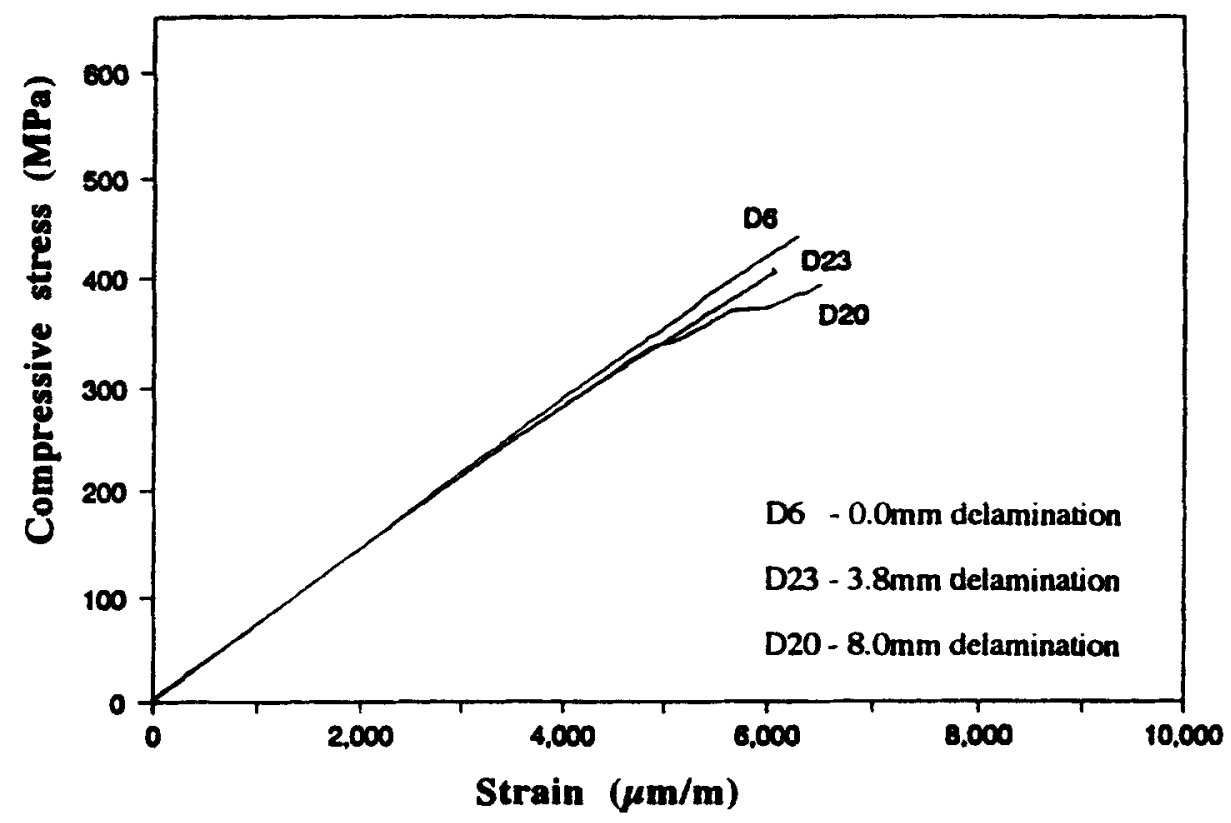

Figure 9. Stress/strain history of AWJ-machined Gr/Ep compression specimens.

Subsequent analysis showed that surface roughness resulting from trimming with diamond abrasive cutters had essentially no influence on the ultimate compression strength. However, although surface roughness of AWJ specimens had notable but limited influence on the ultimate compression strength within comparable roughness of diamond abrasive specimens, exit ply delamination had significant influence. The relationship between surface roughness and ultimate compression strength from both processing techniques are shown in figures $11 \mathrm{a}-\mathrm{b}$. The correlation between exit ply delamination resulting from AWJ trimming and ultimate compression strength is also shown in figure 11c.

Similar to compression specimen analysis, characteristics of the flexure specimen machined surface indicative of each fabrication method were quite different, but no distinction in ultimate strength could be made from average surface roughness. Mean and characteristic strengths calculated for the three specimen batches from Weibull statistics were nearly equivalent.

Typical preliminary impact test results (Arola \& Ramulu 1995) are shown in figure 12. A typical load and the load-line displacement profile for a diamond-saw specimen is shown in figure 12a. The features of the impact event of interest include the peak load, peak fracture load, and the total energy to failure. Representative load and load-line displacement profiles for PCD and AWJ specimens are shown in figure 12b-d. Unfortunately, the dynamic sensors available to record specimen displacement in this study had a travel limit of $5 \mathrm{~mm}$. Therefore, the energy to complete failure, represented by the integral of the total incremental load displacement curve, was not available. Hence, the energy calculated to the limit of the displacement sensors is essentially the total energy to fracture. Averaged values for the impact properties of 100 specimens are listed in table 3 . Only minimal differences in the peak impact load were noted from impact testing. However, the difference 


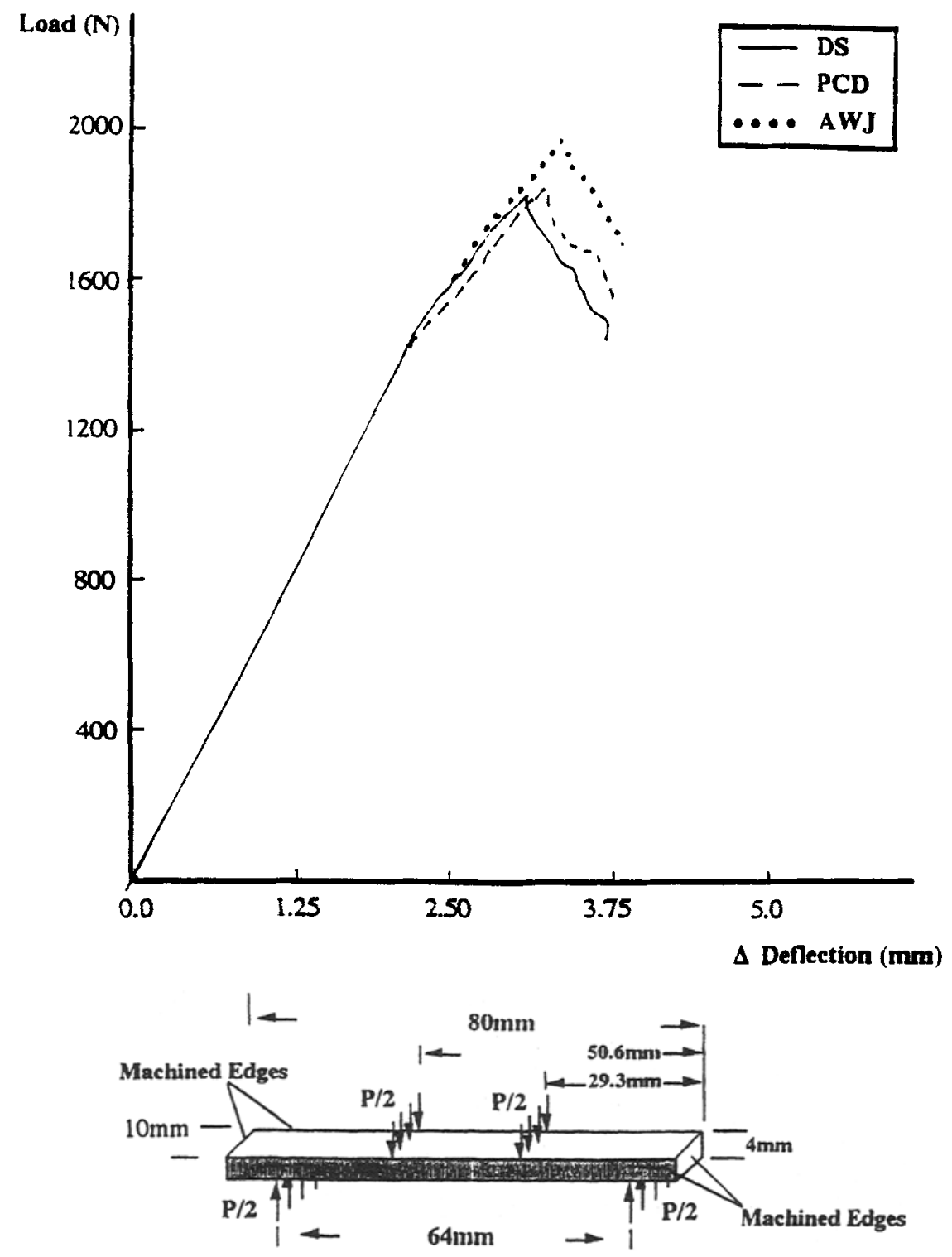

Figure 10. Flexure specimen geometry and loading configuration. 

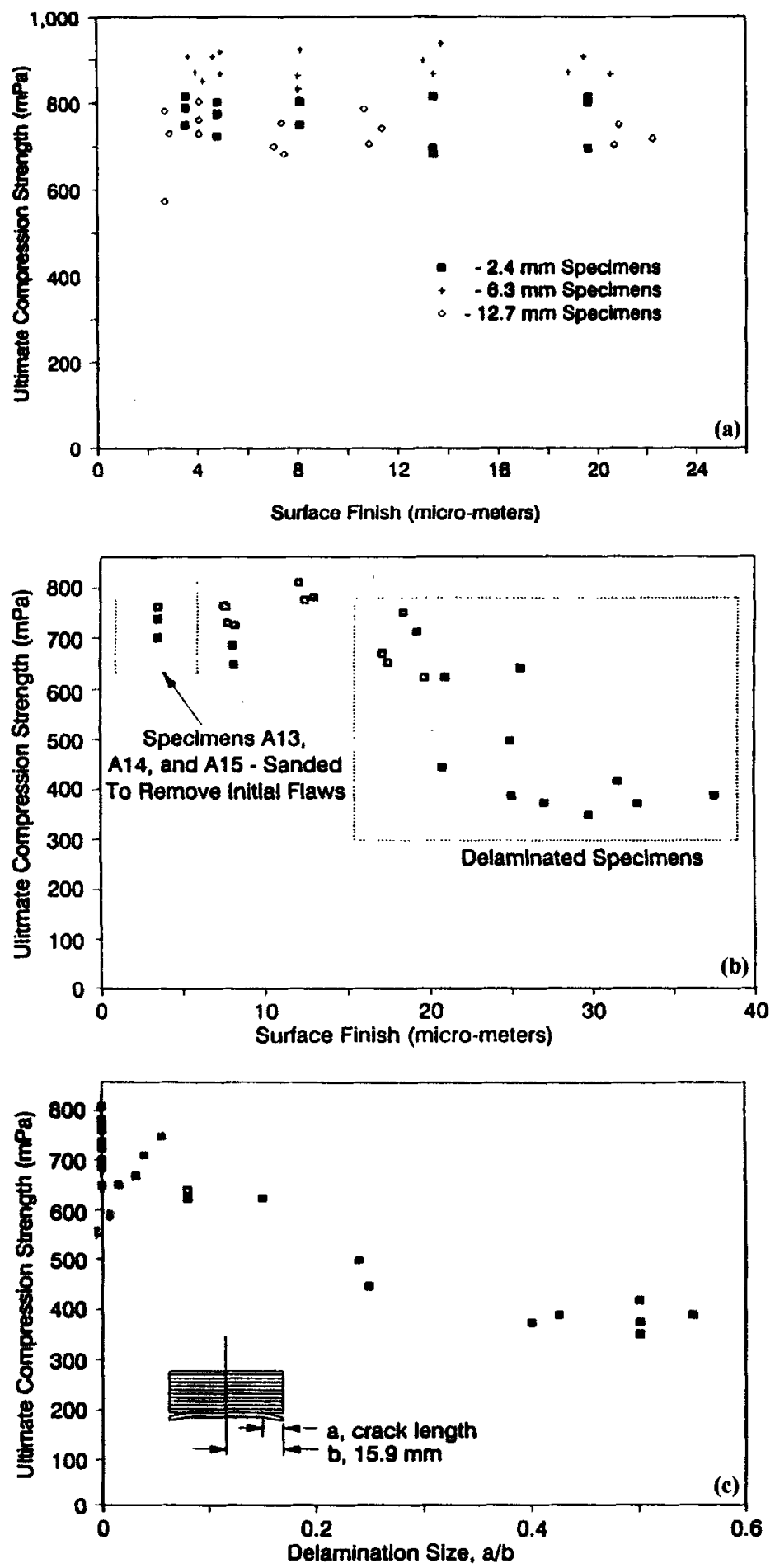

Figure 11. Influence of processing on the ultimate compression strength. (a) Machined with diamond abrasive cutters; (b) AWJ-machined; (c) AWJ compression strength vs. exit ply delamination. 

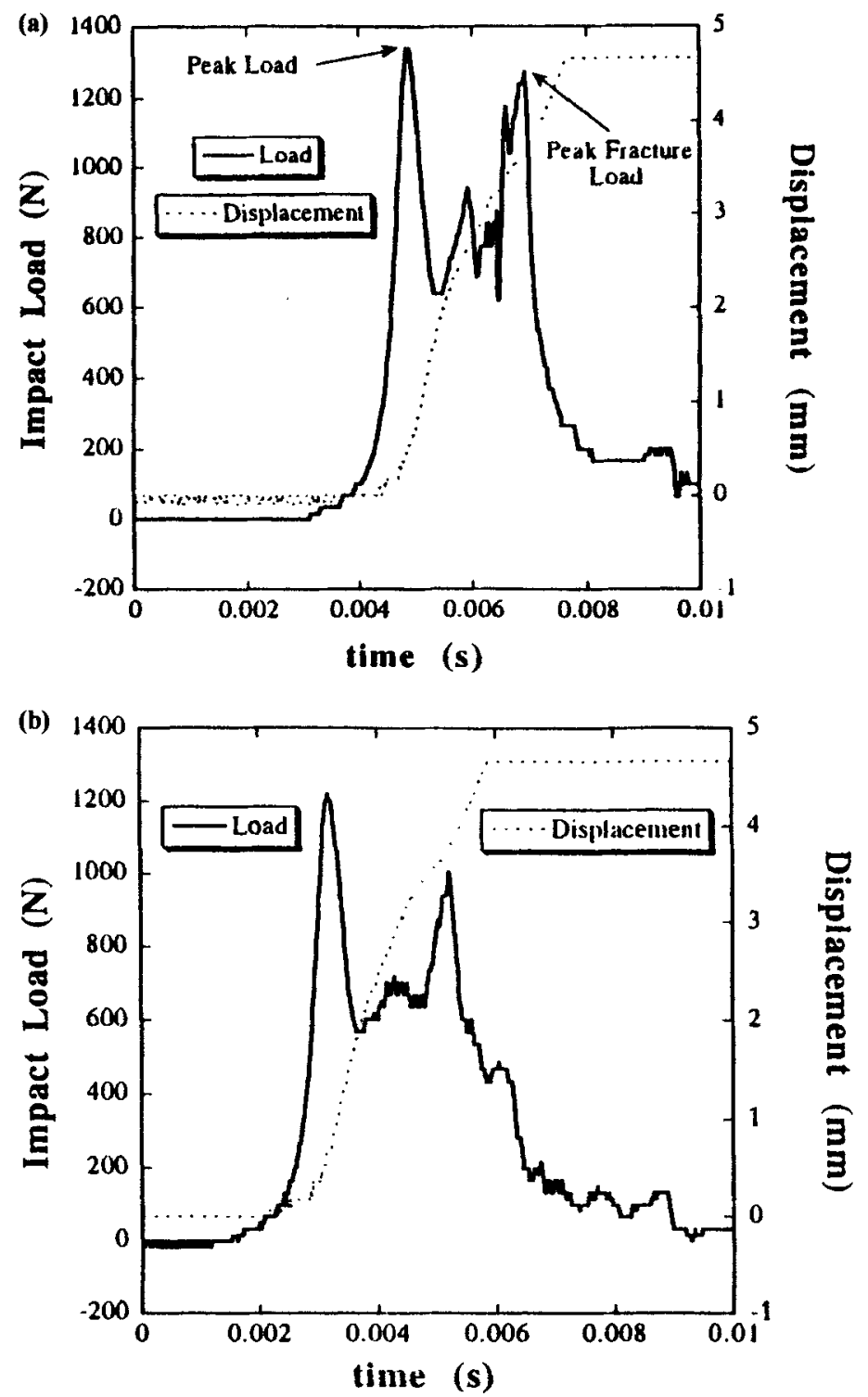

Figure 12. (a and b. Caption on facing page.) 

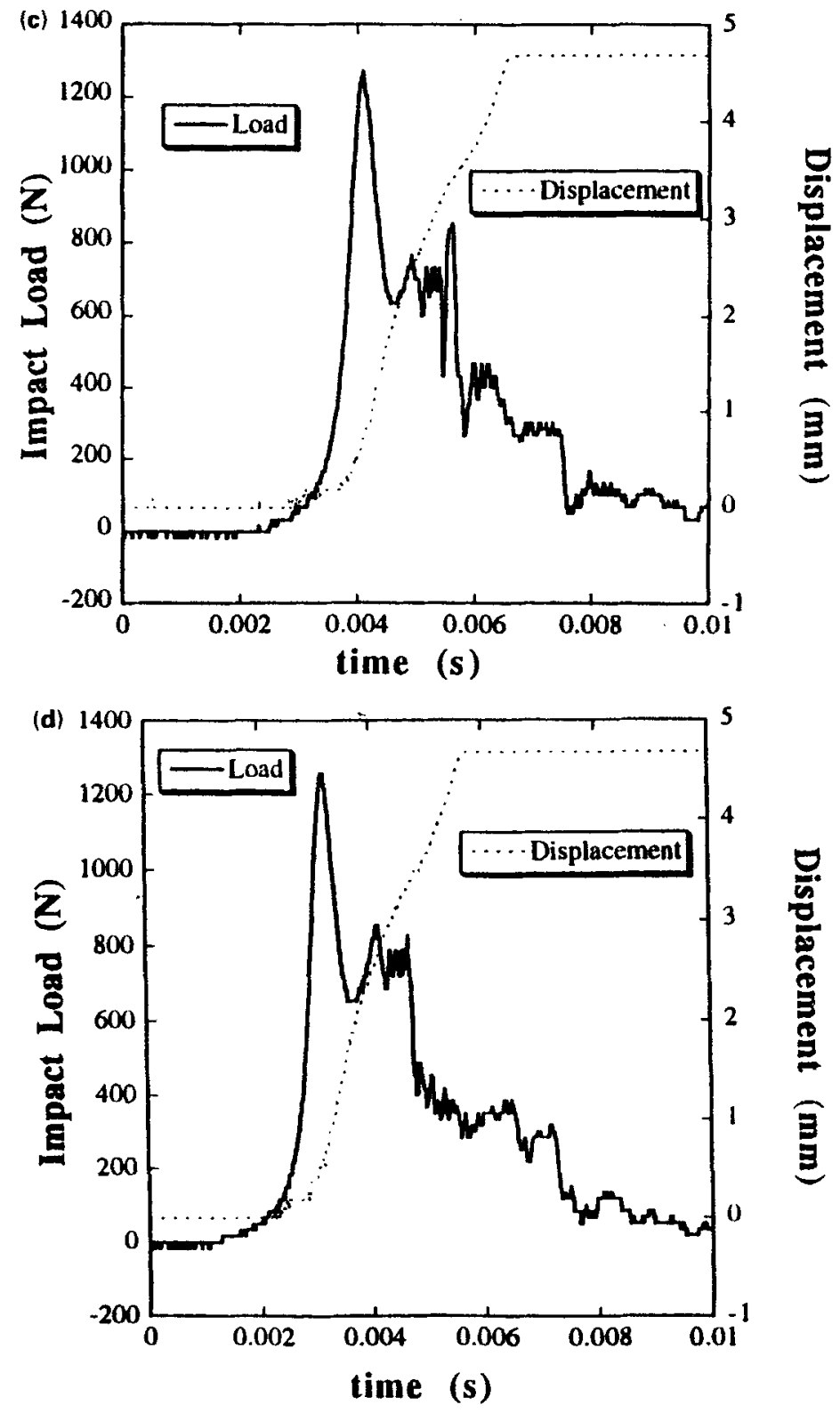

Figure 12. Typical recorded load, load-line displacement, (a) diamond-saw, (b) PCD, (c) AWJ (a) (no. 50 garnet) . (d) AWJ (c) (no. 150 garnet). 
Table 3. Impact loading failure parameters.

\begin{tabular}{lccc}
\hline Machining type & Peak load $(\mathrm{N})$ & Peak fracture load $(\mathrm{N})$ & Energy to fracture $(\mathrm{N} \cdot \mathrm{m})$ \\
\hline Diamond-saw & $1285.8 \pm 60.8$ & $1057.9 \pm 207.9$ & $3.43 \pm 0.42$ \\
Planer (PCD) & $1235.1 \pm 29.8$ & $1028.0 \pm 155.1$ & $3.51 \pm 0.15$ \\
AWJ (a) & $1215.0 \pm 67.6$ & $817.7 \pm 72.0$ & $3.04 \pm 0.15$ \\
AWJ (b) & $1258.1 \pm 44.6$ & $904.5 \pm 107.5$ & $3.24 \pm 0.14$ \\
AWJ (c) & $1262.6 \pm 48.1$ & $958.4 \pm 206.9$ & $3.29 \pm 0.26$ \\
\hline
\end{tabular}

in peak fracture load and the energy dissipated varied with the method of machining. As expected, the diamond-saw had the highest peak load to failure and energy to fracture.

Scanning electron microscope analysis of failed specimens suggested that features resulting from traditional trimming with PCD tools may have given rise to unique failure propagation. Extensive macro-cracking along the $-45^{\circ}$ plies occurred in PCD-trimmed specimens extending through the entire specimen length. Conversely, diamond-saw and AWJ-machined specimens exhibited much higher post-failure integrity with far fewer macro-cracks. Results from compression, flexure and impact tests suggest that surface finish alone does not degrade a laminate. Delaminations incurred during trimming control residual strength.

\subsection{Conclusion}

Machining-induced surface features discussed in this study had limited influence on bulk strength of the $\mathrm{Gr} / \mathrm{Ep}$ material but may affect the impact or fatigue strength where flaws in material structure become more important. Preliminary results of impact tests indeed revealed the effect of edge-finishing on the peakloads to failure. In these loading configurations, fibre pullout and fibre matrix debonding, as well as the high values of surface roughness, cause flaw propagation and accelerated failure. Further study of the effects of machining-induced damage on composite material performance will address this issue. Studies by Howarth \& Strong (1990) combined with results from this preliminary investigation confirm that aspects of net-shape manufacturing, including the particular technique used and the resulting cut characteristics, may influence the structural integrity of FRP's. However, the mechanisms responsible for reduction in mechanical performance are not clearly understood.

\section{Summary}

Investigation of machining mechanisms and machining induced edge effects on the structural integrity of FRP materials was conducted. Consistent with previous reports, results from compression, flexural and impact testing to failure suggest that particular features of the machined surface may not only affect the bulk strength, but also the initiation and propagation of failure. Therefore, for predicting the future applications of FRP materials, based on the current state of applicable net-shape manufacturing technology, additional investigations are necessary to thoroughly understand the effects of the methods of manufacturing on the structural integrity of FRP materials. 
The author acknowledges the financial support from National Science Foundation through the Presidential Young Investigators Award, Grant No. MSS-895864, the Washington Technology Center, and the Boeing Company. Thanks are extended to graduate students D C Wang, C W Wern, K C Colligan and D Arola for their assistance, and Drs Malakondaiah and E Prasad of DMRL at Hyderabad for their help with the manuscript.

\section{References}

Abrate S, Walton D A 1992a Machining of composite materials. Part I: Traditional methods. Compos. Manuf. 3: 75-83

Abrate S, Walton D 1992b Machining of composite materials. Part II: Non-traditional methods. Compos. Manuf. 3: 85-94

Arola D, Ramulu M 1994 Machining induced surface texture effects on the flexural properties of a graphite/epoxy laminate. Composites 25: 822-833

Arola D, Ramulu M 1995 Manufacturing effects on the impact properties of graphite/epoxy composite. Proceedings of the 10th Annual Technology Conference of American Society of Composites (in press)

ASTM 1986 Standard test methods for the flexural properties of unreinforced and reinforced plastics and electrical insulating materials. ASTM D790M

Colligan K 1993 Machined edge effects on the compression strength of graphite/epoxy. MS thesis, University of Washington, Seattle

Colligan K, Ramulu M 1992 The effect of edge trimming on composite surface plies. Manuf. Rev. 5: $274-283$

Ghasemi Nejjad M N, Chou T-W 1990 Compression behaviour of woven carbon fibre-reinforced epoxy composite with molded in and drilled holes. Composites 21: 33-40

Griswold N C, Massarweh W A, Hough C L 1989 Morphological structures in analysis and inspection of hole quality in fiber composites. J. Testing Eval. 17: 281-286

Ho-Cheng H, Dharan C K H 1990 Delamination during drilling in composite laminates. J. Eng. Ind. 112: 39-47

Howarth S G, Strong A B 1990 Edge effects with waterjet and laser beam cutting of advanced composite materials. In 35th International SAMPE Symposium, pp 1685-1697

Inoue H, Ido M 1986 Study on the cutting mechanism of GFRP. In Proceedings of Int. Symp. on Composite Materials and Structures, Beijing, pp 1110-1115

Jamil S J, Chambers A R 1991 Evaluation of surface quality of drilled holes in composite materials after high speed drilling. In Advance machining for quality and productivity (incorporating the 2nd International Conference on the Behavior of Materials in Machining, 1991), pp 70-76

Kaneeda T 1991 CFRP Cutting mechanism. Trans. North Am. Manuf. Res. Inst. SME 19: 216-221

Kinkaid R 1988 Quality holes in composites with PCD cutting tools. Cutting Tool Eng. 40: 50-52

König W, Wulf C, Graf P, Willersceid H 1985 Machining of fiber reinforced plastics. Ann. CIRP 34: 537-547

Koplev A 1980 Cutting of CFRP with single edge tools. In Proc. of 3rd Int. Conf. on Composite Materials, Paris, pp 1597-1605

Koplev A, Lystrup A, Vorm T 1983 The cutting process, chips and cutting forces in machining CFRP. Composites 14: 371-376

Krisnamurthy R, Santhanakrishnan G, Malhotra S K 1992 Machining of polymeric composites. In Machining of Composites (Columbus, OH: ASM) pp 139-148 
Lin H J, Lee Y J 1992 Strength of composite laminates with continuous fiber around a circular hole. Compos. Struct. 21: 155-162

McCarty J E 1993 Design and cost viability of composites in commercial aircraft. Composites 24: $361-365$

Mehta M, Reinhart T J, Soni A H 1992 Effect of fastener hole drilling anomalies on structural integrity of PMR-15/Gr composite laminates. In Machining of composites (Columbus, $\mathrm{OH}$ : ASM) pp 113-126

Miller R K 1991 Waterjet cutting: Technology and industrial applications (Liburn, GA: Fairmont)

Mortimer J 1987 New technology brings quality to manufacture. Ind. Robot 14: 103-104

Park J 1991 Study on the effect of PCD tool geometry on the machining of graphite/epoxy composite materials. MS thesis, University of Washington, Seattle

Pengra J J, Wood R E 1980 The influence of hole quality on graphite/epoxy composite laminates. In Proceedings of the AIAA/ASME/ASCE/AHS 21st Structures, Structural Dynamics and Materials Conference AIAA Paper 80-0777, pp 687-693

Philips J L, Parker R T 1987 Fastener hole considerations. In Engineered materials handbook, Composites (Columbus, OH: ASM) pp 712-715

Pipes R B, Pagano N J 1970 Interlaminar stresses in composite laminates under uniform axial extension. J. Compos. Mater. October: 538-548

Ramulu M, Arola D 1993 Water jet and abrasive water jet cutting of unidirectional graphite/epoxy composite. Composites 24: 299-308

Ramulu M, Arola D 1994 The influence of abrasive waterjet cutting conditions on the surface quality of graphite/epoxy laminates. Int. J. Mach. Tools Manuf. 34: 295-314

Ramulu M, Wern C W, Garbini J L 1993 Effect of fiber direction on surface roughness measurements of machined graphite/epoxy composite. Compos. Manuf. 4: 39-51

Riggs J P 1984 Emerging non-metallic structural materials used for airframes and other demanding applications. Mater. Soc. 8: 351-376

Sadat A B 1988 Machining of graphite/epoxy composite material. SAMPE Q. 19: 1-4

Sakuma K, Seto M 1983 Tool wear in cutting glass-fiber-reinforced plastics. Bull. JSME 26: 1420-1427

Tagliaferri V, Di Ilio A, Crivelli Visconti I 1985 Laser cutting of fibre reinforced polyesters. Composites 16: 317-325

Tagliaferri V, Caprino G, Diterlizzi A 1990 Effect of drilling parameters on the finish and mechanical properties of GFRP composites. Int. J. Mach. Tools Manuf. 30: 77-84

Wang D H 1993 Machining characteristics of graphite/epoxy composites. Ph D thesis, University of Washington, Seattle

Wang D H, Ramulu M, Wern C W 1992 Orthogonal cutting characteristics of graphite/epoxy composite material. Trans. NAMRI/SME 20: 159-165

Wang D H, Ramulu M, Arola D 1995a Orthogonal cutting mechanisms of graphite/epoxy composite, Part I: Unidirectional laminate. Int. J. Mach. Tools Manuf. 35: 1623-1638

Wang D H, Ramulu M, Arola D 1995b Orthogonal cutting mechanisms of graphite/epoxy composite, Part II: Multi-directional laminate. Int. J. Mach. Tools Manuf. 35: 1639-1648

Wern C W 1991 Surface characteristics of machined graphite/epoxy composites. M S thesis, University of Washington, Seattle

Wood R E 1978 Graphite/epoxy composite hole quality investigation. In 10th National SAMPE Technical Conference, Materials Synergisms 10: 636-650

You S-S, Chou T-W 1988 Strength of woven-fabric composites with drilled and molded holes. In 8th Conference on Composite Materials: Testing and Design, ASTM STP 972, pp 423-437 